Apidologie, 1986, 17 (2), 159-174

\title{
SOME ASPECTS OF THE UTILIZATION OF POLLEN ANALYSIS IN ECOLOGICAL RESEARCH
}

\author{
M. RAMALHO and A. KLEINERT-GIOVANNINI \\ Departamento de Ecologia Geral do Instituto de Biociências \\ da Universidade de São Paulo, 05508, São Paulo, Brasil
}

\section{SUMMARY}

This paper discusses some methodological aspects of pollen analysis designed to obtain quantitative data which can be used for ecological studies. The analysis was performed with four pollen samples and four honey samples taken from Plebeia remota Holmberg. The results demonstrated that variations in the number of microscope slides and the degree of magnification at which they were examined did not limit or affect the power of the analysis. A 1000 grain random count using three slides was considered adequate for this type of approach.

\section{INTRODUCTION}

There are three basic difficulties in the analysis of pollen in food gathered and stored by bees : 1) the identification of the pollen grains, which is inherent to applied palynology as a whole and depends on the degree of knowledge of the regional flora; 2) whether or not use acetolysis for honey, which affects the identification and representation of plant constituents and the dynamism of the analysis; and 3) the quantification of plant constituents, which permits greater or lesser exploitation of data from the ecological standpoint, depending on the number of grains counted and on the level of identification achieved.

Acetolysis has been incorporated as a method for pollen analysis of honey, although with some reservations. Louveaux et al. (1970) did not include it among the methods of melissopalynology, although they did so in 1978. GADBIN (1979) and LIEUX (1980) refuted some of its supposed inconveniences, such as the differential destruction of pollen grains and of the elements indicating honeydew. The use of acetolysis is generally defended or opposed by considering the stage of development of pollen, and melissopalynology studies, and by the characteristics of the flora from a regional standpoint. 
In Brazil, BARTH (19.70 a, b, c, d, 1971) characterized the pollen content of honey from various regions without using acetolysis. Iwama and Melhem (1979) introduced this methodology by modifiying the technique of LouvEAuX et al. (1970) to analyse honey from Tetragonisca angustula angustula Latreille. This was pionnering work, with a high degree of importance from the methodological standpoint.

Special attention must be paid to the quantification of plant constituents. VERGERON (1964) used statistical calculations to determine the number of pollen grains which should be counted in honey sampies in order to obtain precise percentages for representation. LouvEAUX et al. (1970, 1978) presented various quantitative methods which are generally accepted in melissopalynology, among them the establishment of pollen frequency classes based on counts of a small number of pollen grains (100-300). ENGELS and Dingemans-BAKELS (1980), and SOMmeIJER et al. (1983) also used frequency ciasses, but with different representation intervals from those proposed by LouveAux and collaborator.

The present paper deals with a methodology which is aimed at obtaining quantitative data for convenient exploitation from the ecological standpoint, based on the analysis of the pollen content of the food gathered by bees.

\section{MATERIAL AND METHODS}

The colonies were kept at the Bee Laboratory of the Bioscience Institute of the University of São Paulo. The University campus is located in the urban region of São Paulo city, at longitude $46^{\circ} 43^{\prime}$ 'West and latitude $23^{\circ} 33^{\prime}$ South, and at an altitude of $735-765$ meters. The gardens of the Bioscience Institute have diversified native and foreign species of plants. The area also contains a small semi-deciduous forest of native species, covering aproximately 10 hectares.

Four pollen samples (A1-A4) and four honey samples (A5-A8), taken from three colonies of Plebeia remota Holmberg, were analyzed. The honey was collected using a disposable hypodermic syringe $(2-4 \mathrm{ml})$, and the pollen was collected with a pair of tweezers $(3-5 \mathrm{~g})$, depending on the availability of food in the bees new storage pots.

The pollen samples were treated by the acetolysis method (ERdTMAn, 1960), and the honey samples by that of Louveaux et al. (1970), as modified by IWAMA and Melhem (1979). The amount of material used to prepare microscope slides was variable, in accordance with the amount of sediment in the centrifuge tubes. A small block of glycerinated gelatin (approximately $2 \mathrm{~mm}^{3}$ ) was immersed in the tube bottom so as to be covered by a thin layer. The block was divided up for use on three or four slides. This operation was reapeted three times so as to obtain a total of ten slides.

In the case of the pollen samples, since there was a large amount of sediment, a small proportion was used to prepare the slides. Care was taken to make sure the blocks of glycerinated gelatin came into contact with all the sediment.

The pollen grains were identified by comparing them with the materials from the pollen collections owned by the University of São Paulo Biosciences Institute (the site of collection) 
and the Botanics Institute of the São Paulo State Secretariat for Agriculture, and by consulting the literature on regional work.

Percentages were calculated on the basis of a count of 1000 pollen grains, with a $0.06-0.07$ confidence interval (VERGERON, 1964).

Concentration was estimated for each sample on the basis of a count of the pollen content of five fields per slide for four slides,magnified 400 times, together with the diversity of pollen types for the total content of three slides and 1000 units, for counts of three and ten slides at different degrees of magnification $(I=200$ times; $I I=400$ times; $I I I=1000$ times $)$.

The data were subjected to a homogeneity test to compare the percentage values of pollen types in the samples. The uniformity of occurence of the « $c$ » pollen categories (pollen grains of different species) in «1» samples (counts in the situations considered) can be estimated by means of the distribution

$$
\sum_{i=1}^{1} \stackrel{\mathrm{k}}{=}=1_{\text {Eik }}^{\mathrm{c}}
$$

which tends towards the distribution of chi-squared with $(\mathrm{I}-1) \times(\mathrm{c}-1)$ degrees of freedom. Values for Eik are estimated by the mathematical expression :

$$
\frac{\mathrm{EIIIik}+\mathrm{EXik}}{\mathrm{nIII}+\mathrm{nX}}=\frac{\mathrm{E}^{\prime} \text { IIIik }}{\mathrm{n} \mathrm{III}}
$$

where : E IIlik $+\mathrm{E} \mathrm{Xik} \mathrm{=} \mathrm{total} \mathrm{number} \mathrm{of} \mathrm{grains} \mathrm{in} \mathrm{category} « \mathrm{c} »$ observed in both samples of 1000 grains ( $\mathrm{X}$ versus III slides; magnification $\mathrm{I}$ versus II and II versus III);

E' IIIik = expected value for sample III (count on three slides or at different degrees of magnification);

$\mathrm{n} \quad=$ number of grains counted in each sample.

NB : Pollen grains with frequency of less than 5 were put together into one category.

The Student's t-test (hypothesis test) for the difference between the population means when the samples are depending and paired (e.g. for each diversity value $\langle Y$ » in a count of 1000 grains on three slides there are corresponding analogous observations on ten slides) can be applied to the pollen diversity values observed for each count of a sample. In this case, the influence of the number of slides or of the degrees of magnification used for counts on the pollen grain diversity obtained can be estimated :

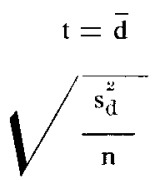

$$
\text { where } \begin{aligned}
\mathrm{d}_{\mathrm{i}} & =\mathrm{Y}_{\mathrm{IIIi}}-\mathrm{Y}_{\mathrm{xi}} \\
\overline{\mathrm{d}} & =\frac{\mathrm{d}_{\mathrm{i}}}{\mathrm{n}} \\
\mathrm{s}_{\mathrm{d}}^{2} & =\frac{\sum_{\mathrm{i}}=1\left(\mathrm{~d}_{\mathrm{i}}-\mathrm{d}\right)^{2}}{\mathrm{n}-1}
\end{aligned}
$$




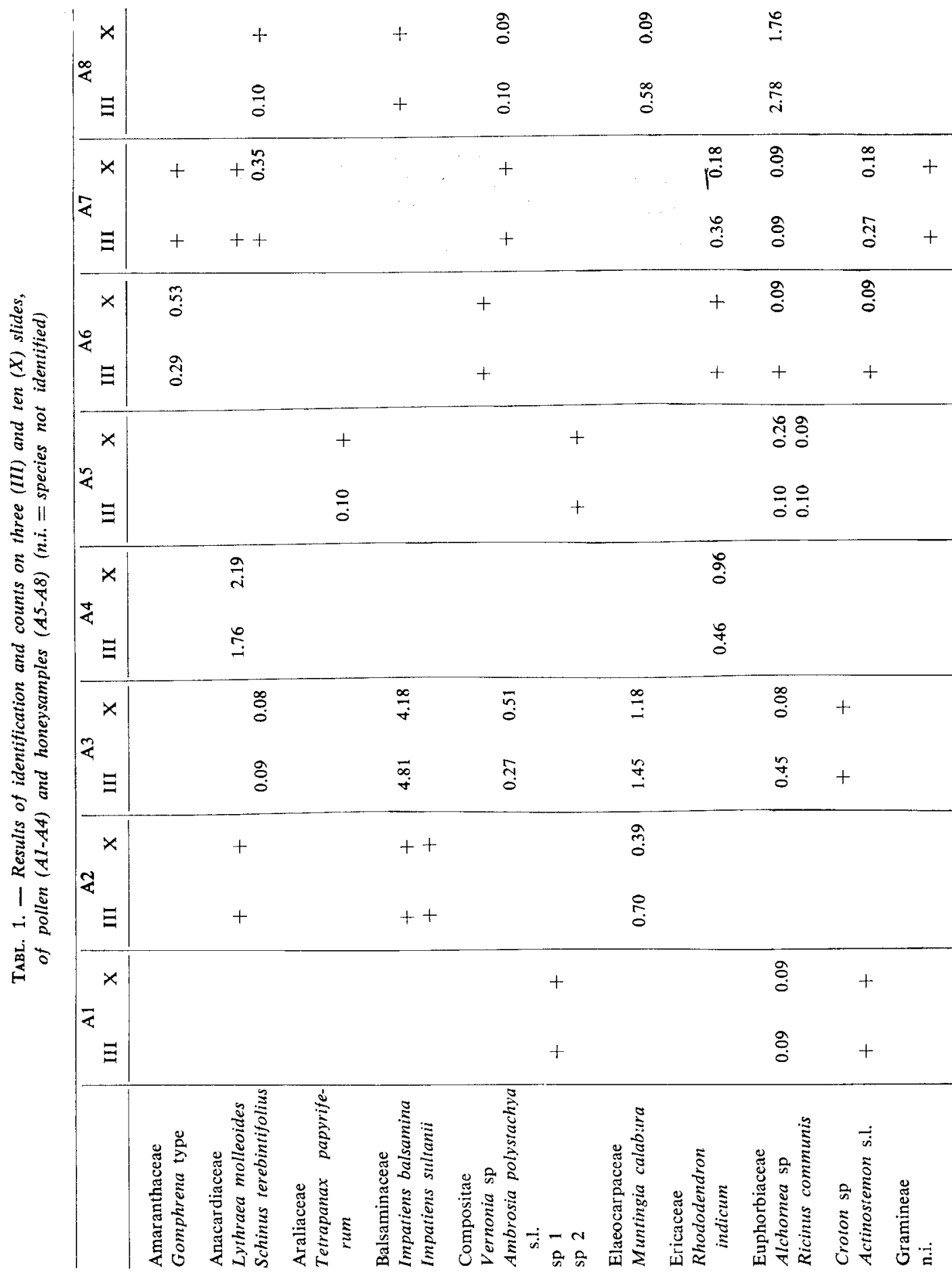




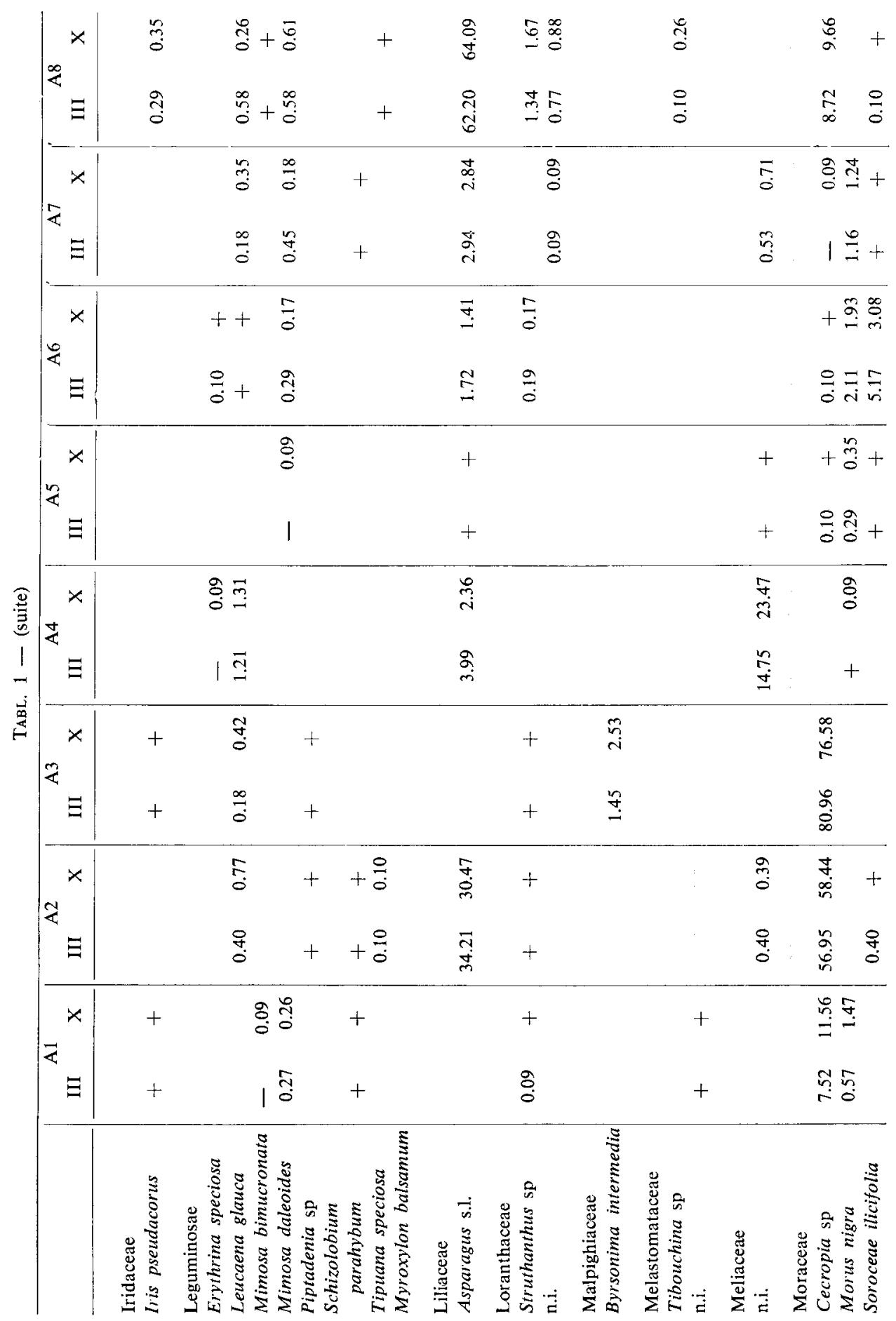




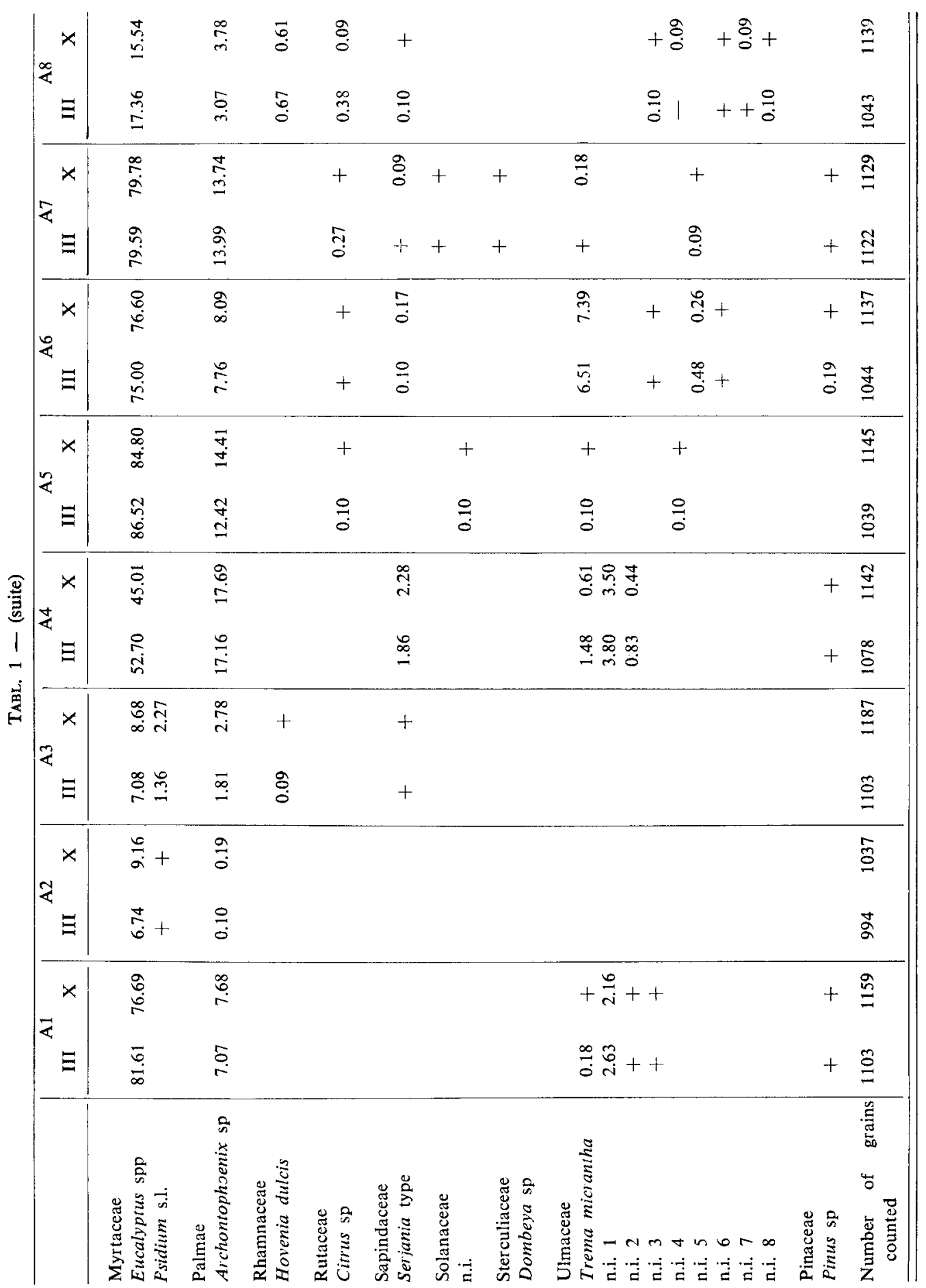




\section{RESULTS}

Table 1 lists the data on identification and counts. The number of unidentified pollen grains is due in part to the present state of knowledge about pollen from the local flora. The Eucalyptus species were grouped together owing to the difficulty of differentiating them during counting, although during the identification stage this was possible. Hybridzation is very common with this genus, however, so that pollen grains from it have characteristics which cannot easily be individualized at a specific level.

Considering polien types with a representation of over $10 \%$, the percentage variation between counts on three and ten slides can be explained as due to chance. The deviations obtained are close to the limits of the confidence interval (0.06-0.07) and are thus acceptable.

In sample $\mathrm{A} 4$, the irregular movement of the grains on the slide probably increased the variability of the representation of the species. The size of pollen from Meliaceae (Cabralea s.l.) (with a polar view equal to $40 . \mathrm{mm}$ and equatorial view to 43 and $38 \mu \mathrm{m})$ and Archontophoenix $(58 \times 34 \mu \mathrm{m})$ make a sufficient contrast with that of Eucalyptus (approximately $25 \mathrm{~lm}$ ) ; in particular, the «cubic » form of the first type makes it more susceptible to barriers to movement. This situation favours and accumulation of larger grains near the areas where the glycerinated gelatin touches the slide; once the cover slip has been placed in position, the Eucalyptus pollen grains rapidly accompany the spreading movements, whereas this is not the case with the other two types. It can be assumed that the effects of this differentiated distribution become more intense as the number of subsamples on each slide are reduced (fewer fields used for counting). In this case, a count of ten slides would be more susceptible to sampling errors.

The following results were obtained from applying the homogeneity test to the values from counts on III and $\mathrm{X}$ slides :

\begin{tabular}{c|c|c|c}
\hline \hline Sample & d.f. & $\chi^{2}$ & $\chi_{\text {c }}^{2}$ \\
\hline A5 & 2 & 1.176 & 5.991 \\
A2 & 3 & 3.226 & 7.815 \\
A1 & 5.885 & 11.070 \\
A7 & 0.178 & 11.070 \\
A6 & 5 & 3.815 & 12.592 \\
A3 & 6 & 6.133 & 15.507 \\
A8 & 8 & 5.509 & 16.919 \\
A4 & 9 & 19.937 & 16.919 \\
\hline
\end{tabular}

N.B. : $\chi_{c}^{2}=$ critical chi-squared at $5 \%$ significance level. 
We accept the hypothesis that both methods of counting are homogeneous. Sample A4 is an exception (this can be explained by the high degree of heterogeneity in the distribution of pollen grains on the slides, as already mentioned, and should not be put down to the methodology under discussion in this paper).

Table 2 highlights some quantitative parameters. It was found that the total evaluation of the pollen content of three slides led to an overestimation of the diversity in the samples, since the count values were far smaller. On the other hand, there were no significant fluctuations in diversity when comparing results from ten and three slides, which could be explained as caused solely by the use of this methodological parameter. The estimated pollen grain concentration shows that there were significant variations between samples (1.6-92.6 grains per field). This might have an effect on the diversity and percentages of pollen grains counted.

TABL. 2. - Distribution of pollen grains in samples: number of pollen types observed in total content of three slides and in counts of 1000 units in three (III) and ten (X) slides; mean concentration of samples (number of grains per field, magnified 400 times)

\begin{tabular}{c|c|c|c|c}
\hline \hline Samples & Total & III & $X$ & Mean concentration \\
\cline { 2 - 4 } A1 & 17 & 9 & 8 & 33 \\
A2 & 16 & 9 & 8 & 40 \\
A3 & 17 & 12 & 11 & 93 \\
A4 & 13 & 11 & 13 & 14 \\
A5 & 15 & 11 & 6 & 10 \\
A6 & 22 & 14 & 13 & 55 \\
A7 & 25 & 13 & 15 & 37 \\
A8 & 25 & 20 & 17 & 2 \\
\hline
\end{tabular}

When the t-test (hypothesis test of the difference between the population means) was applied to the pairs of diversity values (diversity of pollen types for counts on three and ten slides) in table 2 , the results was $t=1.214$. The critical value was obtained at a significance level of $5 \%$ with 7 degrees of freedom :

$$
t_{c}=2.365
$$

Figure 1 shows an attempt to correlate the «concentration» of pollen grains on the slides with the reduction of types observed in the counts (expressed in percentage). However, it would be possible to use the number of species with pollen representation of less than $1 \%$ to correct the distribution of points in this figure. As a comparative example, samples A3 and A7 show, in the former case, a smaller range of pollen types apparently counterbalancing the effect of a high «concentration». The variation would seem to increase as the concentration increases. Sample A7 (which countained 21 pollen types with less than $1 \%$ and 


\section{Pollen}

\section{variation \%}

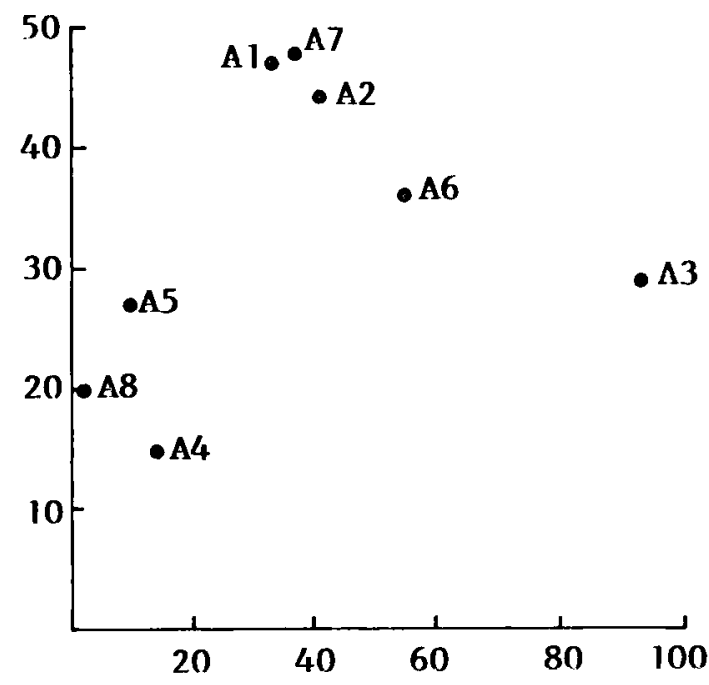

Mean pollen concentratjon

Fig. 1. - Variation in the number of pollen types (\%)

when results of counts of three slide are compared with total observed on three slides in terms of mean pollen concentration of samples

«medium concentration $»)$ was selected to estimate the influence of the increase of the microscope field on percentage values and the occurence of pollen types on three sets of slides.

The results given in table 3 show that the 1000-grain count tends to conceal any existing percentage discrepancies which might crop up owing to the use of different degrees of magnification of the microscope field for different counts. Furthermore, no significant difference was observed in the pollen type diversity over the three groups of slides (table 4). This demonstrates the good sampling representation of each group.

The homogeneity test was applied to the data in table 3 taking as a reference the results obtained in the count with magnification II (400 times). In other words, « $»$ categories were compared at I $\times$ II and II $\times$ III.

\begin{tabular}{c|c|c|c}
\hline Magnification & d.f. & $\chi^{2}$ & $\chi_{0}^{2}$ \\
\cline { 2 - 3 } I $\times$ II & 5 & 0.925 & 11.070 \\
II $\times$ III & 5 & 2.817 & 11.070 \\
\hline
\end{tabular}


TABL. 3. - Percentages of pollen types in counts of sample A7 at different degrees of magnification $(I=200$ times; $I I=400$ times;

$I I I=1000$ times $; n=$ number of grains counted; n.i = species not identified)

\begin{tabular}{l|r|r|r}
\hline \hline & I & II & III \\
\hline Eucalyptus spp & 77,35 & 77,17 & 76,75 \\
Archontophoenix sp & 12,67 & 13,97 & 15,83 \\
Asparagus s.1. & 4,51 & 3,95 & 3,51 \\
Meliaceae (n.i.) & 1,54 & 1,16 & 1,00 \\
Morus nigra & 1,44 & 1,56 & 0,60 \\
Other & 2,49 & 2,21 & 2,30 \\
$\mathrm{n}$ & 1042 & 1038 & 998 \\
\hline
\end{tabular}

TABL. 4. - Number of pollen types observed in counts of three slide groups in sample A7 at different degrees of magnification

\begin{tabular}{l|r|r|r}
\hline & I & II & III \\
\hline Slides & & & \\
$1,2,3$ & $(980) 15$ & $(1017) 13$ & $(1008) 15$ \\
$4,5,6$ & $(1006) 15$ & $(988) 14$ & $(1011) 17$ \\
$7,8,9$ & $(1042) 14$ & $(1038) 14$ & $(998) 14$ \\
\hline
\end{tabular}

Obs. : The numbers in paranthesis indicate the amount of counted grains.

We accept the hypothesis that the results do not depend on the degree of magnification used when counting.

The t-test for the diversity values (table 4) observed at different degrees of magnification (taking degree II as a reference point) gave the following results :

\begin{tabular}{c|c|c|c|}
\hline \hline Magnification & d.f. & $\mathbf{t}$ & $\mathbf{t}_{\mathrm{c}}$ \\
\cline { 2 - 3 } I X II & 2 & 1.733 & 4.303 \\
II X III & 2 & 1.900 & 4.303 \\
\hline
\end{tabular}

We accept that the difference between the diversity values depending on the methodology used (number of slides and different degrees of magnification) is not significant. 


\section{DISCUSSION}

The utilization of acetolysis was chosen in view of the fact that a negligible number of cases presented problems when the reference slide collection of over 400 species of angiosperms in the area was being established. Few pollen grains became transparent or appeared fragmented on the slides, while none at all was destroyed in such a way as to prevent characterization and possible identification in the honey and pollen samples. GADBIN (1979) reached similar conclusions based on a comparative analysis of acetolyzed and non-acetolyzed honey.

The occurence of indicator of honeydew has been irrelevant in studies performed in this field (Iwama and Melhem, 1979'; Mouga, 1984 ; KleinertGIOVANNINI, 1984 ; IMPERATRIZ-FonSECA et al., 1984), while the actual supply of this product would seem to be scarce in terms of the characteristics of the local flora, as would the frequency with which bees gather it. Lieux (1980) found the same situation through an analysis of honey in the southeast of the U.S.A. He argued that depending on geographic origin, the appearance of spores, fungus hyphae, algae, etc., might be scarce and hence negligible when interpreting the results of analysis, even if acetolysis is used.

Finally, it can be concluded that in an ecological study which makes use of pollen analysis, with a specific objective and a comparative approach (for example, the sharing of floral resources among bees in spite of gathering in non-floral resources), any sampling errors by the use of acetolysis, e.g., become acceptable or even negligible through the standardization of methodology.

Difficulties with identification had to be overcome in the name of maintaining the dynamics of the analysis. Further to this point, it is worth stressing that the major advantage of acetolysis lies in the possibility of identifying pollen grains over the long term, a task which could be worth undertaking depending on its relevance to the improvement of the research project.

Nevertheless, most unidentified pollen grains present insignificant representation and should not affect an ecological treatment of the data to a great extent. This demonstrates the validity of setting up a reference slide collection, even though the spatial boundaries of the cataloguing process and the recognition of the internal floral diversity of the community have not yet been defined and exhausted (above all owing to the diversity of the flora and the sporadic variation in the number of species, caused by the unpredictable presence of ephemeral and allochthonous elements, which may be a common task within modified communities).

This appears to be a common situation in environments about which palynological knowledge is insufficient. ABSY and KeRr (1977), AbSY et al. (1980), and 
ENGel and Dingemans-BaKels (1980), for example, encountered difficulties in determining the pollen grains present in the food of some stingless bees in the Amazon region and in Surinam. BARTH (1970a-d) also makes some remarks on the difficulty of identifying pollen in Brazilian honey.

Within certain limits, however, ecological investigation can dispense with identification, although it requires discrimination between pollen forms, and would not therefore be jeopardized. This is why, for example, all the Eucalyptus species were grouped together during the counts in the present study, so as to avoid introducing errors of sampling. In this case, it would be useful to differentiate a group rather than a species, providing this was suited to the aims of the study (which would not necessarily be limited).

In his statistical analysis of the pollen content of honey, VERGERON (1964) admitted that the pollen grains with high percentages (around 50\%) followed the binomial law, while those with a very low representation (about $1 \%$ ) behaved like the sequential elements of Poisson's law. This condition is a result of the basic and fundamental characteristic of the system-heterogeneity, in terms both of very different frequencies and of casual distribution of pollen grains in preparations.

Our results show that variations in the number of slides and degree of magnification at the levels investigated do not limit the theoretically possible power of the analysis : in the first case because the influence of chance on sampling would be increased by a reduction in the number of slides (from 10 to 3), leading to a drop in the amount of pollen grains subsamples from the sediment contained in the centrifuge tubes; in the second, because it would limit the sampled areas of the slides (fewer fields) under lesser degrees of magnification - an effect analogous to that of concentration, but with an increase in the size of each field, hence without a real reduction in the area sampled on each slide.

The uniformity of sampling confirmed by applying the homogeneity test is especially important, as it estimates what occurs with all the $n$ pairs of values in each sample and hence depends on the total similarity of the result of the counts.

The hypothesis test for the difference between population means runs up against the problem of the representation of grains with less than $1 \%$. The acceptance of our hypothesis, even in view of this factor which tends to increase the differences, shows that the results do not depend on the number of slides or the magnification of the microscope field (within the limits analyzed).

The eight samples analyzed were found to contain different situations, resulting from the diversity, representation and concentration of pollen. Despite these peculiarities, the observation and counting of 1000 grains at random on three slides provided good results. 
It can be admitted that there are two valid option. Identification may be limited, with efforts being focused basically on the naming of different forms of pollen (which limits but does not hinder an ecological approach) and with few pollen grains being sampled in order to determine pollen categories. This approach presents certain disadvantages from the ecological standpoint, because they are more or less arbitrary and divergent depending on the research group, and hinders certain mathematical analyses which depend on precise percentage values. Alternatively, work may be designed to obtain detailed results which require exhaustive identification and precision in quantitative data. In this context, what matters is that the approach may sometimes fall short of palynological objectives in the strict sence of the term.

\section{ACKNOWLEDGEMENTS}

The authors wish to thank Dr. Therezinha S. Mецнем for help given during the performance of this work and to Fundação de Amparo à Pesquisa do Estado de São Paulo (FAPESP - process $\left.n^{\circ} 82 / 1401-9\right)$ for financial support.

Received for publication in August 1985.

Accepted for publication in January 1986.

\section{RESUMÉ \\ QUELQUES ASPECTS DE L'UTILISATION DE L'ANALYSE POLLINIQUE DANS LA RECHERCHE EN ECOLOGIE}

La mise au point de méthodes analytiques applicables au miel et au pollen stockés par les abeilles dans le but d'obtenir des données qui soient exploitables du point de vue écologique présente quelques difficultés. Dans le présent travail nous avons discuté brièvement l'influence, d'une part de l'acétolyse des pollens, d'autre part du niveau taxonomique de leur identification. Dans notre domainee, alor que l'étude de la niche trophique de plusieurs espèces d'abeilles ne fait que commencer, nous avons montré que les erreurs dues à l'utilisation de l'acétolyse sont négligeables, surtout en matière d'analyse quantitative, tandis que du point de vue de l'amélioration de la connaissance palynologique de la région la méthode présente des avantages certains. Nous considérons que le niveau taxonomique de l'identification que l'on peut atteindre donne la limite des possibilités de discussion des résultats mais ne s'oppose pas à leur approche écologique. Dans le cadre de nos études la différenciation entre les formes polliniques peut suffire à la description des variables que constituent la diversité des récoltes et les chevauchements dans l'exploitation des ressources par les abeilles.

En ce qui concerne le traitement du sédiment pollinique obtenu après centrifugation, nous avons montré que sa division en sous-échantillons pour obtenir un plus grand nombre de préparations microscopiques dont chacune permet l'examen de 1000 unités polliniques n'accrôt pas nécessairement les possibilités de l'analyse compte tenu des objectif́s écologiques visés. L'examen de 10 ou de 3 préparations microscopiques apporte des résultats similaires en ce qui concerne la diversité et les proportions des types polliniques (tableaux $1,2,3$ et 4 ); le test $t$ d'homogénéité confirme notre hypothèse. C'est la raison pour laquelle nous avons choisi de nous limiter à l'examen de trois préparations microscopiques dans les analyses portant sur les aliments stockés par les abeilles. 


\section{ZUSAMMENFASSUNG \\ EINIGE ASPEKTE DES GEBRAUCHS DER POLLENANALYSE IN DER ÖKOLOGISCHEN FORSCHUNG}

Die Entwicklung analytischer Methoden, die anwendbar sind auf den von den Bienen eingelagerten Honig und Pollen, mit dem Zweck, Daten zu gewinnen für die ökologische Forschung, stößt immer noch auf einige Schwierigkeiten. In der voriiegenden Arbeit diskutieren wir einerseits den Einfluß der Acetolyse des Pollens andererseits des Klassifizierungsniveaus bei der Identifikation. In unserem Bereich konnten wir, obwohl die trophische Nische einiger Bienenarten erst in ihren Anfängen erforscht ist, zeigen, daß die Fehler, die durch den Gebrauch der Acetolyse entstehen, vernachlässigbar sind, vor allem bei quantitativen Analysen, während im Hinblick auf eine Verbesserung der palynologischen Kenntnisse über die Region unsere Methode gewisse Vorteile bietet. Wir stellten fest, daß das Klassifizierungsniveau bei der Identifikation, das erreicht werden kann, die Grenzen für die Diskussion der Resultate setzt, aber nicht gegen einen ökologischen Ansatz opponiert. Im Rahmen unserer Untersuchung genügte die Unterscheidbarkeit zwischen den Pollenformen zur Beschreibung der Variablen, die die Verschiedenheit der Trachten und das übereinandergreifen der Ausnutzung der Ressourcen durch die Bienen verdeutlichen.

Bei der Behandlung des Pollensediments, das durch Zentrifugation gebildet wird, konnten wir zeigen, daß die Aufteilung in Unterproben mit dem Ziel, eine größere Zahl von mikroskopischen Präparaten zu erhalten, von denen jedes die Untersuchung von 1000 Polleneinheiten erlaubt, nicht notwendigerweise die Möglichkeiten einer Analyse unter ökologischen Gesichtspunkten verbessert. Die Untersuchung von 10 oder von 3 Präparaten ergab, was die Verschiedenheit und den Anteil der Pollentypen betraf, ähnliche Resultate (Tab. 1, 2, 3 und 4); ein T-Test auf Homogenität bestätigte unsere Hypothese. Aus diesem Grunde haben wir uns entschlossen, uns auf die Untersuchung von 3 mikroskopischen Präparaten zu beschränkten, wemn eine Analyse von eingelagertem Futter der Bienen angefertigt werden soll.

\section{REFERENCES}

ABsY M.L., KerR W.E., 1977. - Algumas plantas visitadas para obtenção de pólen por operárias de Melipona seminigra merrilae em Manaus. Acta Amazônica, 7 (3), 309-315.

Absy M.L., Bezerra E.B., Kerr W.E., 1980. - Plantas melíferas utilizadas por 2 espécies de Melipona da Amazônia. Acta Amazônica, 10 (2), 271-181.

Barth O.M., 1970a. - Análise microscópica de algumas amostras de mel. 1 - Pólen dominante. An. Acad. brasil. Ciên., 42 (2), 351-366.

Barth O.M., 1970 b. - Análise microscópica de algumas amostras de mel. 2 - Pólen acessório. An. Acad. brasil. Ciên., 42 (3), 571-592.

Barth O.M., 1970 c. - Análise microscópica de algumas amostras de mel. 3 - Pólen isolado. An. Acad. brasil. Ciên., 42 (4), 747-772.

Barth O.M., 1970 d. - Análise microscópica de algumas amostras de mel. 4 - Espectro polínico de algumas amostras de mel do Estado do Rio de Janeiro. Rev. bras., Biol., 30 (4), 575-581.

Barth O.M., 1971. - Análise microscópica de algumas amostras de mel. 6 - Espectro polínico de algumas amostras de mel dos Estados da Bahia e do Ceará. Rev. bras., Biol., 31 (4), 431-434.

Engel M.S., Dingemans-Bakels F., 1980. - Nectar and pollen resources for stingless bees (Meliponinae, Hymenoptera) in Surinam (South Amerioa). Apidologie, 11 (4), 341-350. 
Gadbin C., 1979. - Interest of acetolysis in melissopalynology. Apidologie, 10 (1), 23-28.

imperatriz-Fonseca V.L., Kleinert-Giovannini A., Cortopassi-Laurino M., Ramalho M., 1984 a. - Hábitos de coleta de Tetragonisca angustula angustula Latreille (Apidae, Meliponinae). Bolm Zool., 8, 115-131.

Iwama S., Melhem T.S., 1979. - The pollen spectrum of the honey of Tetragonisca angustula angustula Latreille. Apidologie, 10 (3), 275-295.

Kleinert-Giovannini A., 1984. - Aspectos do nicho trófico de Melipona marginata marginata Lepeletier (Apidae, Meliponinae). MSc Thesis. Instituto de Biociências. Universidade de São Paulo. São Paulo, 79 p.

LiEuX M.H., 1980. - Acetolysis applied to microscopical honey analysis. Grana, 19, 57-61.

Louveaux J., Maurizio A., Vorwohl G., 1970. - Methods of melissopalynology. Bee World, 51 (3), 125-138.

Louveaux J., Maurizio A., Vorwohl G., 1978. - Methods of melissopalynology. Bee World, 59 (4), 139-157.

Mouga D.M.D.S., 1984. - Atividade de coleta de Paratrigona subnuda (Moure) (Apidae, Meliponinae). MSc Thesis. Instituto de Biociências. Universidade de São Paulo. São Paulo, $117 \mathrm{p}$.

Sommeijer M.J., Rody G.A. de, Punt W., Bruijn L.L.M. de, 1983. — A comparative study of foraging behavior and pollen resources of various stingless bees (Hymenoptera, Meliponinae) and honeybees (Hymenoptera, Apinae) in Trinidad, West-Indies Apidologie, 14 (3), 205-224.

VERGERon P., 1964. - Interprétation statistique des résultats en matière d'analyse pollinique des miels. Ann. Abeille, 7 (4), 349-364. 